\title{
TIME-DEPENDENT EFFECT OF DIFFERENT INTRACANAL MEDICAMENTS ON DENTIN MICROHARDNESS AND DISLOCATION RESISTANCE OF MTA USED DURING REGENERATIVE ENDODONTIC TREATMENT
}

\author{
Hamdy M.R*, Elddamony E.M*** and Abdelgawad R.A*
}

\begin{abstract}
Objectives: This study was designed to measure and compare dentin microhardness and MTA (ProRoot, Dentsply Tulsa Dental, Tulsa, OK) dislocation resistance (DR) used in regenerative endodontic treatment (RET) after application of three different intracanal medication(ICM) for 2,4 and 12 weeks' time intervals.
\end{abstract}

Material and methods: One-hundred sixty eight human maxillary central incisors were selected for the study. Teeth were cut apically $12 \mathrm{~mm}$ below and coronally $2 \mathrm{~mm}$ above the cementoenamel junction. Canals were instrumented up to instrument F5 (ProTaper Universal, Dentsply Maillefer, Ballaigues, Switzerland), then Peeso drills (Mani, Tochigi, Japan) were used from No. 1 up to No. 6 , passing $1 \mathrm{~mm}$ beyond the apical foramen to obtain larger root canals. Between every 2 consecutive instruments $2 \mathrm{~mL}$ of $2.5 \%$ sodium hypochlorite $(\mathrm{NaOCl})$ used for canals irrigation, final flush using $5 \mathrm{~mL}$ of $2.5 \% \mathrm{NaOCl}$ and $5 \mathrm{~mL}$ of $17 \%$ ethylene-diamine-tetra-acetic acid (EDTA, Sigma) followed by $10 \mathrm{~mL}$ of distilled water. Samples were randomly divided according to the type of the ICM used inside the canal into 4 equal groups $(n=42)$; Group 1: Double antibiotic past(DAP) paste: 1:1 mixture of ciprofloxacin (Cipro $500 \mathrm{mg}$, Schering Plough, Kenilworth, NJ, USA) and metronidazole (Flagyl $500 \mathrm{mg}$, Sanofi-Aventis, Tours, France), Group 2: Bioactive glass powders (BAG S53P4) of $60 \mathrm{~mol} \% \mathrm{SiO}_{2}, 12 \mathrm{~mol} \% \mathrm{P}_{2} \mathrm{O}_{5}$ and $28 \mathrm{~mol} \% \mathrm{CaO}$ composition were prepared through sol gel processing route, all reagents were purchased from Sigma-Aldrich(Dorset, UK). Group 3: Non-setting Calcium hydroxide ( $\mathrm{CH})$ (Merk, Germany) was used, and finally, Group 4(Control): where no ICM was applied. Samples were kept in saline solution for either 2, 4, and 12 weeks, randomly selected samples from each group $n=14$ at each interval where intracanal medication removed, half of them $n=7$ were subjected to dentin Vickers microhardness test, in remaining half $n=7$ MTA (ProRoot, Dentsply Tulsa Dental, Tulsa, OK) placed $4 \mathrm{~mm}$ deep into the coronal third of the roots having a 4 mm-long chamber, samples were stored for a week at $37{ }^{\circ} \mathrm{C}$ at $100 \%$ humidity to allow the complete setting of MTA, then push-out test was used to measure the dislocation resistance DR of MTA. Collected data were analyzed using a two-way ANOVA followed by Bonferroni's post-hoc test was used for pair-wise comparisons $(\mathrm{P} \leq 0.05)$.

* Lecturer in Endodntic Department, Faculty of Dentistry, Suez Canal University

** Lecturer in Dental Materials Department, Faculty of Dentistry, Suez Canal University 
Results: showed that both DAP, CH groups of intracanal medication and time interval had a significant decreasing effect on dentine microhardness and MTA dislocation resistance the DR of MTA ( $P$-value $<0.001)$. While, BAG group`s results revealed significant increase in dentine microhardness and MTA dislocation resistance $(P$-value $<0.001)$. The time factor displayed a significant effect on dentin microhardness and the DR of MTA (P-value <0.001).

Conclusion: Regarding situations in this study, intracanal medications type and duration of application used in root canals disinfection through RET must be carefully chosen to avoid negative effect on dentin microhardness or DR of MTA jeopardizing the success of the treatment. BAG (S53P4) showed promising results, further studies needed to complete investigations about it as intracanal medication in RET.

KEYWORDS: Regenerative endodontic treatment, MTA, Bioactive glass, Dentin microhardness, Dislocation resistance.

\section{INTRODUCTION}

Achieving the goal of endodontic treatment while dealing with immature teeth is a great challenge, considering capability to disinfect weak, thin, infected dentinal walls and poor crown/root ratio together with establishing apical seal are jeopardizing their entity ${ }^{1}$. Apexification using long term calcium hydroxide application or mineral trioxide aggregate artificial apical plug application has been traditionally used for management of such cases ${ }^{2}$. However such treatment modalities take long time and proved inability to reinforce weak incomplete roots $^{3}$, moreover long term use of calcium hydroxide reduces the roots fracture resistance significantly ${ }^{4}$. The concept of regenerative endodontic treatment (RET) was introduced by Nygaard-Ostby in 1961, but unfortunately there were drawbacks including; apical cytotoxicity, increased risk for tooth fracture, and discoloration ${ }^{5}$. In 2004 the concept was reintroduced to modernistic endodontics by Banchs and Trope ${ }^{6}$ through canal disinfection, bleeding establishment and final sealing with MTA. As long as; a sterile environment is critical for pulp tissue regeneration ${ }^{7}$, so the treatment protocol involves frequent procedures for disinfection of the pulp space using irrigation solutions and effective intracanal medication between sessions ${ }^{8,9}$. Triple antibiotic paste (TAP) containing metronidazole, ciprofloxacin, and minocycline is proved to be a successful regimen for RET in controlling the root canal pathogen ${ }^{10}$.
Unfortunately; minocycline present in this mixture proved the cause of discoloration of treated teeth ${ }^{11}$. Double-antibiotic paste (DAP) containing metronidazole only and ciprofloxacin is an alternative to avoid discoloration been proposed ${ }^{12,13}$. However, these antibiotic formulas are developing bacterial resistance and allergic reactions ${ }^{14}$. Considering these disadvantages, calcium hydroxide $(\mathrm{CH})$ may be another promising alternative because of its antimicrobial properties ${ }^{15}$. However, discouraging information about its effectiveness against E.faecalis because of the buffering action of dentin recorded ${ }^{16}$. Bioactive glass (BAG S53P4) is basically a component system of oxides containing $\mathrm{SiO}_{2}, \mathrm{Na}_{2} \mathrm{O}$, $\mathrm{CaO}$, and $\mathrm{P}_{2} \mathrm{O}_{5}$ was invented by Dr. Hench in 1969 and since then it has been used to treat a variety of medical conditions ${ }^{17,18}$. It possess antibacterial and acid neutralizing properties through $\mathrm{pH}$ increase following alkali ions release in an aqueous environment ${ }^{19}$, reported able to stimulate bone regeneration $^{20}$. Moreover, it has remineralizing effect on the demineralized tooth structure through calcium and phosphate ions releasing ${ }^{21,22}$. The addition of powdered enamel and dentin definitely enhanced its antimicrobial efficacy ${ }^{16}$. Regarding all these promising criteria, BAGs have been studied in variety of uses in dental field including; alveolar ridges augmentation, periodontal pocket treatment, a filler in dental materials, such as restorative materials, cements, pit and fissure sealants, root canal sealer 
and for hypersensitive teeth treatment ${ }^{23-25}$. But, although these amazing properties, its efficacy as intracanal medication for RET hasn't been studied yet. As long as; obtaining the therapeutic effects of intracanal medication requires treatment periods varying from 1 week to several months ${ }^{17,18}$. As a final step during regenerative endodontic treatment; MTA is placed on the coronal part of the root canal which is a biocompatible, conductive, and inductive calcium silicate-based material that is able to bond to dentin chemically ${ }^{27}$. Bond strength of MTA is an important factor since teeth are exposed to occlusal and procedural forces that might dislodge the MTA after its placement ${ }^{28}$. Alterations in dentin surface properties and reduction of its mechanical properties; flexure strength, microhardness and root resistance to fracture during RET steps may influence the bond strength of MTA that placed on the coronal part of the root canal ${ }^{29}$. Therefore, the aim of the present study was to evaluate the time-dependent effect of different intracanal medicaments on the dentin microhardness and dislocation resistance (DR) of MTA.

\section{MATERIAL \&METHODS}

\section{Samples preparation and grouping}

The protocol of this study was approved by the Ethics Committee of Suez Canal University (Protocol No. 229/2019). One hundred sixty eight human maxillary incisors that had been recently extracted were used and immature, carious, cracked, resorbed, or calcified teeth were discarded. The buccolingual and mesiodistal dimensions of the teeth were obtained radiographically and thier mean is calculated and teeth with a maximum of $10 \%$ deviation from the mean in each dimension were included and stored in distilled water/ 4 months till the time of use. The teeth were shortened to 12 $\mathrm{mm}$ apical and $2 \mathrm{~mm}$ above the cemento-enamel junction with a low-speed rotary saw (Isomet, Buhler, Lake Bluff, IL, USA) to standardize the teeth length and mimic immature roots. A single operator instrumented all the canals using a rotary nickel-titanium system (ProTaper Universal, Dentsply Maillefer, Ballaigues, Switzerland). The canals were instrumented up to instrument F5, and then Peeso drills (Mani, Tochigi, Japan) were used from No. 1 up to No. 6 (1.7 $\mathrm{mm}$ in diameter), passing $1 \mathrm{~mm}$ beyond the apical foramen to obtain larger root canals. The canals were irrigated with $2 \mathrm{~mL}$ of $2.5 \%$ sodium hypochlorite $(\mathrm{NaOCl})$ between every 2 consecutive instruments. A final flush was then done using $5 \mathrm{~mL}$ of $2.5 \% \mathrm{NaOCl}$ and $5 \mathrm{~mL}$ of $17 \%$ ethylene-diamine-tetra-acetic acid (EDTA, Sigma) followed by $10 \mathrm{~mL}$ of distilled water. The canals were then dried with paper points (Dentsply Maillefer) ${ }^{30}$. Samples were randomly divided according to the type of the ICM used inside the canal into 4 equal groups (n = 42): Group 1: DAP paste: 1:1 mixture of ciprofloxacin (Cipro $500 \mathrm{mg}$, ScheringPlough, Kenilworth, NJ, USA) and metronidazole (Flagyl $500 \mathrm{mg}$, Sanofi-Aventis, Tours, France) prepared with sterile distilled water (w/v 2.5:1) was delivered into the canals as described by Yassen et al.$^{26}$, was delivered into the canals using a lentulo (Dentsply Maillefer, Ballaigues, Switzerland). Group 2: Bioactive glass powders (BAG S53P4)of $60 \mathrm{~mol} \%$ $\mathrm{SiO}_{2}, 12 \mathrm{~mol} \% \mathrm{P}_{2} \mathrm{O}_{5}$ and $28 \mathrm{~mol} \% \mathrm{CaO}$ composition were prepared through sol gel processing route as previously described by Ting $\cdot{ }^{31}$, all reagents were purchased from Sigma-Aldrich (Dorset, UK). The particle size of 70-710 $\mu \mathrm{m}$ which is not ideal to be used as a medicament was transferred into a sterile glass mortar and pestle, crushed into smaller size and then passed through a sieve having mesh size of $45 \mu \mathrm{m}$ suitable to be used as a medicament, powder was mixed with sterile saline in the ratio of 1.5:1 (wt/vol) to obtain a paste-like consistency ${ }^{32}$, ${ }^{33}$. Group 3: Non setting CH (Merk, Germany) was used. $\mathrm{CH}$ powder was mixed with sterile saline in the ratio of $1.5: 1 \mathrm{wt} / \mathrm{v}$ to obtain a paste ${ }^{34}$, delivered into the canals as described previously. Group 4(Control): where no ICM was applied. 


\section{Intracanal medicaments application}

All canals including control group samples were apically sealed using modeling wax (Dentsply DeTrey, Bois Colombes, France) to ensure containment of the ICMs inside the root canal throughout the required duration, and the coronal orifices were sealed with glass ionomer cement (Fuji, GC, Tokyo, Japan). All samples were kept in saline solution, which was replenished every 7 days to avoid dehydration throughout the evaluation period, which lasted up to 12 weeks. After 2, 4, and 12 weeks, randomly selected samples from each group $n=14$ (representing the samples of each group at each interval). The temporary filling material was removed with a size 3 round bur (Dentsply Maillefer) under water cooling, followed by the removal of DAP, BAG, and $\mathrm{CH}$ using $2 \mathrm{~mL}$ of 2.5 $\% \mathrm{NaOCl}$ and $17 \% \mathrm{EDTA}^{35}$, then root canals were dried using absorbent paper points.

\section{Microhardness evaluation:}

After ICM removal at each time interval, half of randomly selected specimens from each group $(n=7)$ were longitudinally sectioned in a buccolingual direction by using a double faced diamond disk at low speed, without passing through the canal space. This was followed by using a chisel $\&$ mallet to split the root. The root segments were then horizontally embedded in auto-polymerizing acrylic resin (Acrostone, Dent Product. Egypt) leaved their dentin surface exposed. The dentin surface was ground flat and smooth with a series of ascending grades of carbide abrasive papers 500, 800, 1,000, and 1,200 grit (Bigo, Dent Product .Germany), under distilled water to remove any surface scratches and finally polished with $0.1-\mathrm{Mm}$ alumina suspension on a rotary felt disc (Microdont LDA. Brazil) to obtain a smooth glossy mirror-like surface ${ }^{36}$. Microhardness measurements were performed using a microhardness tester Tukon 1102 (Wilson Instrument, Norwood, MA) with a Vickers diamond indenter. For each specimen, three indentations were made along a line approximately $0.5 \mathrm{~mm}$ from the root canal space at three different dentin levels (the inner, middle, and outer dentin) using a load of $50 \mathrm{~g} / 10 \mathrm{sec}$. After the load was removed, the diamond-shaped indentations were carefully observed in an optical microscope with a digital camera and image analysis software, allowing the accurate digital measurement of their diagonals. The average length of the two diagonals (usually to the nearest $0.1-\mu \mathrm{m}$ ) was used to calculate the microhardness value ${ }^{37}$. The representative hardness value was obtained as the average of the results for the three indentations.

\section{MTA application}

The remaining half of the specimens at different intervals 2, 4 and 12 weeks from each group $(n=7)$ were used for evaluation of displacement resistance (DR) of MTA at every time interval. After removal of ICM as mentioned before, MTA (ProRoot, Dentsply Tulsa Dental, Tulsa, OK) was prepared in accordance with the manufacturer's instructions and placed $4 \mathrm{~mm}$ deep into the coronal third of the roots with an amalgam carrier having a $4 \mathrm{~mm}$-long chamber. A saline-moistened cotton pellet was placed on top of the MTA to accelerate its homogenous setting. The samples were stored for a week at $37^{\circ} \mathrm{C}$ at $100 \%$ humidity to allow the setting of the MTA completely.

\section{Push-out test}

For each specimen, a transverse section perpendicular to the long axis of the root to obtain a single slice from each root using an Isomet saw (Buehler, Lake Bluff, IL) under water cooling. Slice thickness was adjusted to $2 \mathrm{~mm} \pm 0.1 \mathrm{~mm}$ utilizing a digital caliper (Mitoyo, Tokyo, Japan), while the root canal space was filled with cement material (MTA). A universal testing machine (Model 3345, Instron, Buckinghamshire, UK) was used to dislodge the plug materials utilizing a 1.3-mm-diameter cylindrical plunger in an apical-coronal direction at 
a load cell of $500 \mathrm{~N}$ and a crosshead speed of 0.5 $\mathrm{mm} / \mathrm{min}$ until failure. The maximal force applied to the material before displacement was recorded in newtons $(\mathrm{N})$. The following equation was used to calculate the push-out bond strength (MPa), as an indicator of retention: Push-out bond strength $(\mathrm{MPa})=$ Force to dislodgement $(\mathrm{N}) /$ Adhesive surface area $\left(\mathrm{mm}^{2}\right)$. For each section, the adhesion surface area (A) and MTA retention with intracanal medications was calculated as follows: $(\pi \mathrm{r} 1+\pi \mathrm{r} 2)$ $\times \mathrm{L}$, and the value of $\mathrm{L}$ was calculated as the square root of $(r 1-r 2)^{2}+h^{2}$, where $\pi$ is a constant equal to $3.14, \mathrm{r} 1$ is the smaller radius, $\mathrm{r} 2$ is the larger radius, and $\mathrm{h}$ is the thickness of the section in millimeters as measured using a digital caliper.

\section{Statistical analysis}

Numerical data were explored for normality by checking the distribution of data and using tests of normality (Kolmogorov-Smirnov and Shapiro-Wilk tests). All data showed normal (parametric) distribution. Data were presented as mean and standard deviation (SD) values. Two-way Analysis of Variance (ANOVA) was used to study the effect of material, time and their interaction on mean microhardness and push-out bond strength. Bonferroni's posthoc test was used for pair-wise comparisons when ANOVA test is significant. Pearson's correlation coefficient was used to study the correlation between cement thickness and microhardness. The significance level was set at $\mathrm{P} \leq 0.05$. Statistical analysis was performed with IBM SPSS Statistics for Win- dows, Version 23.0. Armonk, NY: IBM Corp.

\section{RESULTS}

\section{Dentin Microhardness}

The results showed that material regardless of time had a statistically significant effect on mean microhardness table 1. BAG showed the statistically significantly highest mean microhardness. Control showed statistically significantly lower mean value followed by DAP. $\mathrm{CH}$ showed the statistically significantly lowest mean microhardness ( $P$-value $<0.001$, Effect size $=0.991)$.

Time regardless of material also had a statistically significant effect on mean microhardness $(P$-value $<0.001$, Effect size $=0.728), 2$ weeks interval showed the statistically significantly highest mean microhardness followed by 4 weeks showed statistically significantly lower mean value, and 12 interval showed the statistically significantly lowest mean microhardness table(2).

\section{Comparison between materials, time intervals:}

Comparisons between the materials revealed significant difference between mean microhardness of different materials $(P$-value $<0.001$, Effect size $=$ 0.541 ) table (3) and figure (1).At 2 weeks; DAP group showed the statistically significantly highest mean microhardness followed by $\mathrm{BAG}$ and $\mathrm{CH}$ groups with no statistically significant difference between them and Control group showed the statistically significantly lowest mean microhardness.

TABLE (1) The mean, standard deviation (SD) values and results of two-way ANOVA test for comparison between microhardness values of the four materials regardless of time

\begin{tabular}{|c|c|c|c|c|c|c|c|}
\hline \multicolumn{2}{|c|}{ DAP } & \multicolumn{2}{|c|}{ BAG } & \multicolumn{2}{|c|}{$\mathrm{CH}$} & \multicolumn{2}{|c|}{ Control } \\
\hline Mean & SD & Mean & SD & Mean & SD & Mean & SD \\
\hline $88.4^{\mathrm{C}}$ & 11.6 & $119.6^{\mathrm{A}}$ & 16.4 & $82.3^{\mathrm{D}}$ & 13.6 & $94.8^{\text {в }}$ & 0.7 \\
\hline$P$-valu & & (Partia & ared) & & & & \\
\hline
\end{tabular}

*: Significant at $P \leq 0.05$, Different superscripts are statistically significantly different 
TABLE (2) The mean, standard deviation (SD) values and results of two-way ANOVA test for comparison between microhardness at different times regardless of material

\begin{tabular}{|c|c|c|c|c|c|}
\hline \multicolumn{2}{|c|}{2 weeks } & \multicolumn{2}{c|}{ 4 weeks } & \multicolumn{2}{c|}{12 weeks } \\
\hline Mean & SD & Mean & SD & Mean & SD \\
\hline $99^{\mathrm{A}}$ & 2.8 & $96.2^{\mathrm{B}}$ & 14.9 & $93.7^{\mathrm{C}}$ & 28.7 \\
\hline \multicolumn{2}{|l}{-value<0.001* } & Effect size (Partial eta squared) 0.728 \\
\hline
\end{tabular}

*: Significant at $P \leq 0.05$, Different superscripts are statistically significantly different

TABLE (3) The mean, standard deviation (SD) values and results of two-way ANOVA test for comparison between microhardness values with different interactions of variables

\begin{tabular}{|c|c|c|c|c|c|c|c|c|c|c|}
\hline \multirow{2}{*}{ Time } & \multicolumn{2}{|c|}{ DAP } & \multicolumn{2}{|c|}{ BAG } & \multicolumn{2}{|c|}{$\mathrm{CH}$} & \multicolumn{2}{|c|}{ Control } & \multirow{2}{*}{$P$-value } & \multirow{2}{*}{$\begin{array}{c}\text { Effect size } \\
\text { (Partial eta } \\
\text { squared) }\end{array}$} \\
\hline & Mean & SD & Mean & SD & Mean & SD & Mean & SD & & \\
\hline 2 weeks & $102.1^{\mathrm{AE}}$ & 1.3 & $100^{\mathrm{BG}}$ & 1.1 & $98.8^{\mathrm{BE}}$ & 1.7 & $95.2^{\mathrm{C}}$ & 0.9 & $<0.001 *$ & 0.541 \\
\hline 4 weeks & $88.2^{\mathrm{CF}}$ & 1.2 & $120^{\mathrm{AF}}$ & 0.6 & $81.7^{\mathrm{DF}}$ & 0.6 & $94.7^{\text {в }}$ & 0.6 & $<0.001 *$ & 0.976 \\
\hline 12 weeks & $75^{\mathrm{CG}}$ & 3.8 & $138.8 \mathrm{AE}$ & 1.1 & $66.6^{\mathrm{DG}}$ & 1.1 & $94.5^{\text {в }}$ & 0.5 & $<0.001 *$ & 0.993 \\
\hline$P$-value & \multicolumn{2}{|c|}{$<0.001 *$} & \multicolumn{2}{|c|}{$<0.001 *$} & \multicolumn{2}{|c|}{$<0.001 *$} & \multicolumn{2}{|c|}{0.722} & & \\
\hline $\begin{array}{l}\text { Effect size (Partial eta } \\
\text { squared) }\end{array}$ & \multicolumn{2}{|c|}{0.946} & \multicolumn{2}{|c|}{0.973} & \multicolumn{2}{|c|}{0.961} & \multicolumn{2}{|c|}{0.013} & & \\
\hline
\end{tabular}

*: Significant at $P \leq 0.05 . \quad A, B, C, D$ superscripts in the same row indicate statistically significant difference between materials, E,F,G superscripts in the same column indicate statistically significant difference between times

While after 4 as well as 12 weeks BAG group showed the statistically significantly highest mean microhardness followed by Control group then DAP and $\mathrm{CH}$ groups showed the statistically significantly lowest mean microhardness.

Time intervals Comparison revealed that; DAP as well as $\mathrm{CH}$ groups showed the statistically significantly highest mean microhardness at 2 weeks, statistically significant lower mean value at 4 weeks, and statistically significant lowest mean microhardness at 12 weeks. While, BAG group showed statistically significant highest mean microhardness at 12 weeks, statistically significant lower mean value at 4 weeks, and statistically significant lowest mean microhardness at 2 weeks.
Control group; showed no statistically significant difference between mean microhardness at different time intervals.

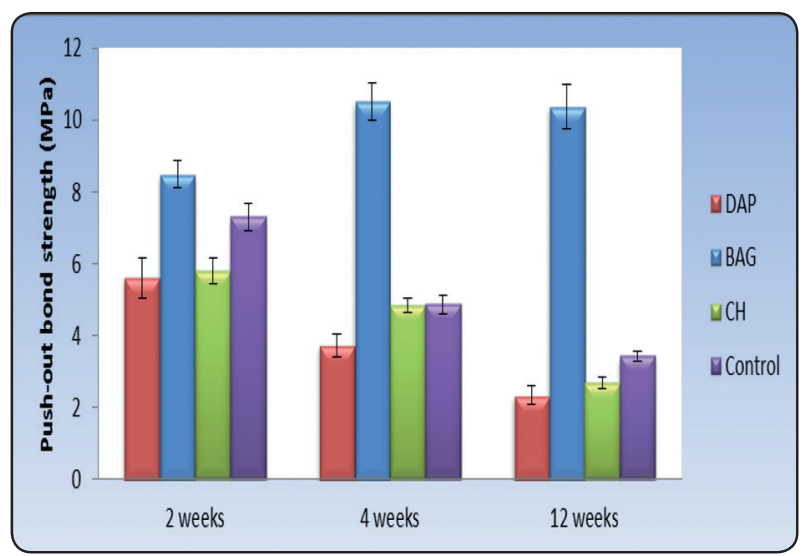

Fig. (1). Bar chart representing mean and standard deviation values for microhardness of different variables 


\section{Push-out bond strength}

The results showed that material regardless of time had a statistically significant effect on mean push-out bond strength $(P$-value $<0.001$, Effect size $=0.853)$ table $(4)$. BAG group showed the statistically significant highest mean push-out bond strength followed by $\mathrm{CH}$ group showed statistically significant lower mean value. There was no statistically significant difference between DAP and control groups; both showed the statistically significantly lowest mean push-out bond strength values.

Time regardless of material showed statistically significant difference between mean push-out bond strength $(P$-value $<0.001$, Effect size $=0.955)$ table (5). 12 weeks interval showed the statistically significantly highest mean push-out bond strength, 4 weeks showed statistically significantly lower mean value, and 2 weeks period showed the statistically significantly lowest mean push-out bond strength.

\section{Comparison between materials, time intervals:}

There were statistically significant differences between mean push-out bond strength of different materials at all intervals table (6), figure (2). At 2 weeks; BAG showed the highest statistically significant mean push-out bond strength values, control groups showed lower statistically significant values. DAP and $\mathrm{CH}$ groups; both showed the statistically significantly lowest mean push-out bond strength values with no statistically significant difference between. After 4 weeks; BAG group showed the statistically significant highest statistically significant mean push-out bond strength values, followed by $\mathrm{CH}$, Control with no statistically significant difference between them, DAP showed the statistically significantly lowest mean push-out bond strength. At 12 weeks; BAG group showed the statistically significantly highest mean pushout bond strength, followed by Control group, then both DAP and $\mathrm{CH}$ groups showed the statistically significantly lowest mean push-out bond strength values, no significant difference between both.

TABLE (4) The mean, standard deviation (SD) values and results of two-way ANOVA test for comparison between push-out bond strength values of the four materials regardless of time

\begin{tabular}{|c|c|c|c|c|c|c|c|}
\hline \multicolumn{2}{|c|}{ DAP } & \multicolumn{2}{|c|}{ BAG } & \multicolumn{2}{|c|}{$\mathrm{CH}$} & \multicolumn{2}{|c|}{ Control } \\
\hline Mean & SD & Mean & SD & Mean & SD & Mean & SD \\
\hline $4.95^{\mathrm{C}}$ & 1.98 & $6.19^{\mathrm{A}}$ & 2.14 & $3.97^{\text {в }}$ & 1.49 & $4.64^{\mathrm{C}}$ & 0.98 \\
\hline$P$-value $<0.001 *$ & & ize $(P a r$ & quared & & & & \\
\hline
\end{tabular}

*: Significant at $P \leq 0.05$, Different superscripts are statistically significantly different

Table (5). The mean, standard deviation (SD) values and results of two-way ANOVA test for comparison between push-out bond strength at different times regardless of material

\begin{tabular}{cccc|c|c|}
\hline & \multicolumn{2}{c}{ 4 weeks } & \multicolumn{3}{c}{12 weeks } \\
\hline Mean & SDeeks & Mean & SD & Mean & SD \\
\hline $3.02^{\mathrm{C}}$ & 0.62 & 1.05 & $6.81^{\mathrm{A}}$ & 1.27 \\
\hline$P$-value & $<0.001^{*}$ & Effect size (Partial eta squared) 0.955 & & \\
\hline
\end{tabular}

*: Significant at $P \leq 0.05$, Different superscripts are statistically significantly different 
TABLE (6) The mean, standard deviation (SD) values and results of two-way ANOVA test for comparison between push-out bond strength values with different interactions of variables

\begin{tabular}{|c|c|c|c|c|c|c|c|c|c|c|}
\hline \multirow{2}{*}{ Time } & \multicolumn{2}{|c|}{ DAP } & \multicolumn{2}{|c|}{ BAG } & \multicolumn{2}{|c|}{$\mathrm{CH}$} & \multicolumn{2}{|c|}{ Control } & \multirow{2}{*}{$P$-value } & \multirow{2}{*}{$\begin{array}{c}\text { Effect size } \\
\text { (Partial eto } \\
\text { squared) }\end{array}$} \\
\hline & Mean & SD & Mean & SD & Mean & SD & Mean & SD & & \\
\hline 2 weeks & $5.62 \mathrm{CE}$ & 0.4 & $8.5^{\mathrm{AE}}$ & 0.54 & $5.81^{\mathrm{CE}}$ & 0.16 & $7.3^{\mathrm{BE}}$ & 0.56 & $<0.001 *$ & 0.804 \\
\hline 4 weeks & $3.74^{\mathrm{CF}}$ & 0.21 & $10.51^{\mathrm{AF}}$ & 0.5 & $4.85^{\mathrm{BF}}$ & 0.27 & $4.87^{\mathrm{BF}}$ & 0.08 & $<0.001 *$ & 0.742 \\
\hline 12 weeks & $2.35^{\mathrm{CG}}$ & 0.35 & $12.37^{\mathrm{AG}}$ & 0.62 & $2.7^{\mathrm{CG}}$ & 0.3 & $3.44^{\mathrm{BG}}$ & 0.39 & $<0.001 *$ & 0.434 \\
\hline$P$-value & \multicolumn{2}{|c|}{$<0.001 *$} & \multicolumn{2}{|c|}{$<0.001 *$} & \multicolumn{2}{|c|}{$<0.001 *$} & \multicolumn{2}{|c|}{$<0.001 *$} & & \\
\hline $\begin{array}{c}\text { Effect size } \\
\text { (Partial eta } \\
\text { squared) }\end{array}$ & \multicolumn{2}{|c|}{0.887} & \multicolumn{2}{|c|}{0.901} & \multicolumn{2}{|c|}{0.818} & \multicolumn{2}{|c|}{0.644} & & \\
\hline
\end{tabular}

*: Significant at $P \leq 0.05 . A, B, C, D$ superscripts in the same row indicate statistically significant difference between materials, $E, F, G$ superscripts in the same column indicate statistically significant difference between times

\section{Time intervals Comparison revealed that;} all study groups was a statistically significant difference between mean push-out bond strength at different times $(P$-value $<0.001$, Effect size $=0.887),(P$-value <0.001, Effect size $=0.901)$, $(P$-value $<0.001$, Effect size $=0.818)$ and $(P$-value $<0.001$, Effect size $=0.644)$, respectively .

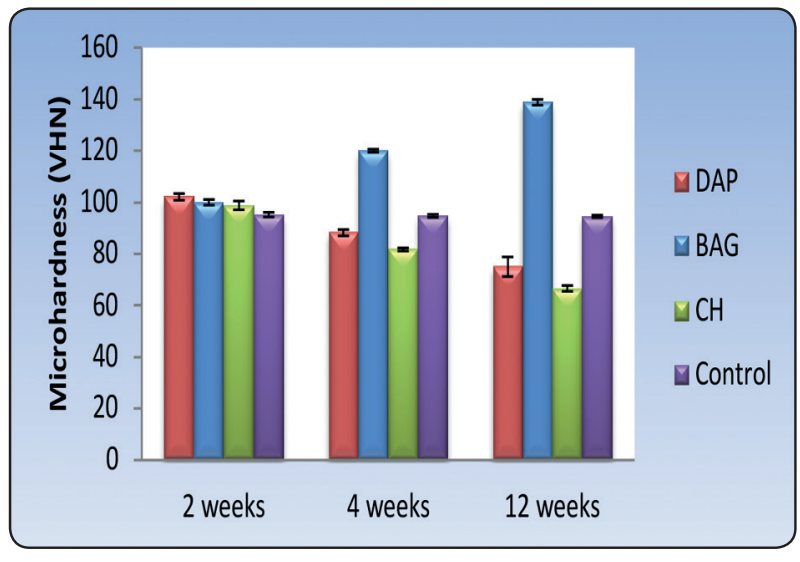

Fig. (2) Bar chart representing mean and standard deviation values for push-out bond strength of different variables

\section{DISCUSSION}

Regenerative Endodontic Treatment (RET) was proposed to achieve a significant increase the thickness and length of immature roots compared to teeth treated with $\mathrm{Ca}(\mathrm{OH}) 2$ apexification or MTA apical plug $^{38,39}$.In RET procedure a gentile mechanical instrumentation is performed to preserve weak roots ${ }^{40}$, as long as disinfection of root canals is mandatory for pulp tissue regeneration ${ }^{9}$. American Association of Endodontists (AAE) recommends root canal irrigation using $1.5 \%$ sodium hypochlorite $(\mathrm{NaOCl})$, then intracanal medicament application during the first visit for 1 - 4 weeks ${ }^{41}$. Upon absence of clinical signs and symptoms confirmation in the following visit, $17 \%$ ethylenediaminetetraacetic acid (EDTA) irrigation in order to release dentin endogenous proteins then bleeding induction to deliver stem cells into the canal and produce natural scaffold ${ }^{42,43}$. Root canals dentin is composed of approximately 70: 20:10\% ratio of inorganic, organic material and of water respectively, $90 \%$ of the organic matter is collagen, which has a major role in mechanical properties of dentin ${ }^{44}$. Root canal irrigation using $\mathrm{NaOCl}$ causes organic matrix oxidation and 
collagen denaturation which changes the mechanical properties, including microhardness due to depletion of the organic phase ${ }^{45,46}$. Oliveira et al. ${ }^{47}$ reported that $1 \% \mathrm{NaOCl}$ decreased root dentin microhardness to depths up to $1,000 \mu \mathrm{m}$ from the canal lumen. Subsequent demineralization of dentin inorganic components by calcium ions chelation effect of EDTA reduces the microhardness ${ }^{36}$. CruzFilho et al. ${ }^{48}$ reported dentin microhardness reduction within the first minute after EDTA application. After then; to complete root canals disinfection, obtain the antimicrobial effect of intracanal medication, it should be placed with time interval 1: 4 weeks' and treatment periods varying from 1 week to several months which may reach up to 11 weeks ${ }^{49}$. But, drawbacks of chemical composition and long duration application including; teeth discoloration, cytotoxicity and decreased fracture resistance were recorded ${ }^{26,50}$. Calcium hydroxide $(\mathrm{CH})$ was one of selected intracanal medications in this study. It is the golden intracanal medication, it has been approved by AAE as an alternative intracanal medication RET ${ }^{5}$. It doesn't cause tooth structure staining and enhance the growth factors and biomolecules release from dentin ${ }^{51}$, it has high $\mathrm{pH}$ of 12 couldn't be maintained due to dentine buffering effect that leads to E. faecalis survival, replication and bacterial biofilm formation which risk the success of $\mathrm{RET}^{37}$. Double antibiotic paste (DAP) was also used in this study owing to its proved efficacy in RET as alternative to TAP to avoid drawbacks of minocycline including; staining of teeth and cytotoxicity against $\mathrm{SCAPs}^{52,53}$.However, bacterial resistance and allergic reactions developed by these antibiotic formulas must be considered ${ }^{54}$. Bioactive glass (BAG S53P4) was invented by Dr. Hench in 1969 and was prepared using the melting technique and ground to fine particles ${ }^{55}$. FDA approved bioactive glass (BAG S53P4) for clinical use ${ }^{56}$. In this study, searching for a better alternative intracanal medication, bioactive glass (BAG S53P4) has been introduced as it proved antimicrobial effect as intracanal medication which inferred to its high $\mathrm{pH}^{57,58}$.
In this study; root canal dentin microhardness measurement was performed using Knoop indenter microhardness test, as it can provide evidence about mechanical changes of root canal walls treated with used chemical agents at different time intervals ${ }^{13}$. In this study; both Calcium hydroxide and double antibiotic paste showed significant decrease in dentin microhardness after 2, 4 and 12 weeks' time interval. These results are related to their effect on dentin chemical structure which directly related to its microhardness. Previous studies ${ }^{59,60}$ studied the effect of calcium hydroxide intracanal medication for 5 weeks or more, suggested that the alkaline $\mathrm{pH}$ of calcium hydroxide denature the organic matrix of the dentine. On the other hand; double antibiotic paste is an acidic material $(\mathrm{pH}=3.4)$, shows a demineralizing effect on the dental hard tissues leading to exposure of collagen-rich matrix of the dentin ${ }^{61}$. In this study; Bioactive glass used as intracanal medication in RET and its effect on root canal dentine is not previously studied. BAG showed significantly highest mean microhardness which significantly increased after 4 and 12 weeks' time intervals. These results can be inferred to its composition contains calcium oxide, sodium phosphor and silicon oxides in specific proportions that are responsible for the ability of the material to strongly bond to calcified tissues producing hydroxyapatite layer on its surface that bonded to hard tissues ${ }^{62}$ and used in calcified tissues regeneration (e.g., bone, enamel) ${ }^{63,64}$. Studies described its remineralizing effect as; BAG dissolved and released their ions forming hydroxycarbonate apatite crystals that obliterate the dentinal tubules more efficiently and protect dentine, inhibit demineralization and facilitate remineralization ${ }^{65-67}$ .Its rule in remineralization of enamel and increase its microhardness also has been reported ${ }^{68}$. The results showed a negative effect of application period of both $\mathrm{CH}$ and DAP where twelve weeks period showed significantly lowest mean microhardness that revealed that the relatively long-term exposure of radicular dentine to intracanal medication might be the reason for the significant reduction in root 
dentin microhardness except for BAG. These interesting results shed a light on Bioactive glass use in RET, further in-virto and in-vivo studies are required to show its bioactive ability enhance regeneration of pulp and root, examine the topography of dentin wall after its application.

Again and according to AAE recommendation, final RET steps are root canal coronal seal through MTA application and tooth coronal final restoration completion $^{5}$. MTA is inductive, conductive, and biocompatible calcium silicate-based material (tri and di calcium silicate) has ability to chemically bond with dentin ${ }^{28}$. MTA displacement resistance (DR) might be influenced by its thickness, dentin humidity, $\mathrm{pH}$ the environment, and dentin pretreatment using either irrigants or medicaments ${ }^{27,69}$. Complete removal of intracanal medication from root canals is mandatory to allow and maintain bonding efficacy of MTA or other permanent biomaterial filling ${ }^{70}$. As complete intracanal medicaments removal is more challenging in RET because of thin dentinal walls that abolish dentin wall debridement protocols Berkhoff et al. 2014. In this study; gentle manual agitation with a ProTaper F5 file accompanied with $5.25 \% \mathrm{NaOCl}$ and $17 \%$ EDTA irrigation ${ }^{71}$. Dentin wall abrasion should be avoided to prevent formation of intacanal medication, smear layer mix that decrease its removal potentials ${ }^{72}$. The integrity of the root filling (MTA)-dentine interface should be preserved as it subjected to displacement forces through function or operative procedures ${ }^{73,74}$. In this study, the MTA dislocation resistance investigated in vitro it terms of bond strength using push-out test that is widely accepted way for evaluation ${ }^{75,76}$. Chemical and mechanical dentin properties change after intracanal medicaments application previously proved to significantly decrease MTA dislocation resistance after 2 weeks application of both TAP \& DAP, and 4 weeks for $\mathrm{CH}^{26}$. In this study; $\mathrm{CH} \&$ DAP showed significant decrease in MTA dislocation resistance starting from 2 weeks, continued decreasing over 4 and 12 weeks intervals both was lower than control group where no intracanal medi- cation used, in accordance with Patil et al $2019^{77}$. Physiochemical bond between MTA \&dentine wall passes through two stages; initial (mechanical) negatively affected by surface roughness and erosions and final (chemical) through formation of an interfacial layer (hydroxyapatite or carbonated apatite) when MTA comes into close contact with dentin, a chemical bond is formed ${ }^{78,79}$. Recently, the use of DAP and $\mathrm{CH}$ intracanal medication proved to cause $\mathrm{Ca}$ and $\mathrm{P}$ alteration and increases dentine surface roughness ${ }^{80,81}$. Moreover, Yassen et al. ${ }^{26}$ explained time-dependent deteriorating dislocation resistance of MTA following CH \&DAP intracanal medication use as follow; collagen degradation of dentin occurs after $\mathrm{CH}$ use, acidic nature of DAP cause dentin demineralization. On the other hand; MTA showed higher DR when used following $\mathrm{CH}$ than DAP intracanal medications in accordance with Shokounejad et al. ${ }^{82}$, who explained the role of alkaline $\mathrm{pH}$ of $\mathrm{CH}$, in addition to reaction of residual $\mathrm{Ca}^{2+}$ ions on remains of intracanal medication with MTA forming calcium carbonate are the cause of higher DR in $\mathrm{CH}$ treated group than DAP group. Others studies ${ }^{83,84}$ attributed this to; less quantity and more superficial $\mathrm{CH}$ intracanal medication remnants than deeply extended DAP resulted in $\mathrm{pH}$ decrease, dentine demineralization, moreover calcium ions chelation deteriorates adhesion of MTA on dentin. In this study; BAG showed a surprising results regarding MTA dislocation resistance which was the highest among used intracanal medications and significantly increased over the study period, as mentioned up to our knowledge no study yet has investigated its effect as intracanal medication on MTA dislocation resistance. The initial (mechanical) high dislocation resistance of MTA could be inferred to large particles size $45 \mu \mathrm{m}^{22}$ of BAG intracanal medication residues that improve the initial (mechanical) bond between MTA and dentin wall, as proved through other studies $^{85,86}$ explained that larger size residues of intracanal medication may improve MTA marginal adaptation due to its physical bond. As well, high $\mathrm{pH}$ value 11.65 of BAG-S53P4 ${ }^{87}$ gives rise to higher disloca- 
tion resistance of MTA as its bond strength proved to become stronger at $\mathrm{pH}$ values higher than $8.4^{41}$. On the other hand; BAG composed calcium oxide, sodium, phosphorus and silica of calcium and phosphate in a proportion mimics bone, it is surface-active material where minerals can bind to hydroxyapatite $^{88,89}$. When BAG used in dentin mineralization or remineralization ${ }^{90}$ it showed the ability to release calcium and phosphate ions and form a bioactive layer hydroxyapatite (HCA) at the interface which is equivalent to the mineral phase of hard human tissues ${ }^{91}$. The (chemical) bond of MTA with dentin walls described by Sarkar et al. ${ }^{28}$ as follow; when MTA is hydrated calcium hydroxide and calcium silicate hydrate (CSH) are formed, then calcium hydroxide interaction with phosphate ions in the body forming amorphous calcium phosphate (ACP), that transforms into interfacial layer (hydroxyapatite or carbonated apatite) that improves bond of MTA. As well, it might chemically bind with BAG residues on the dentin wall giving stronger bond to dentin wall, reasonable explanation for high, increasing DR of MTA all over the treatment intervals.

\section{CONCLUSION}

Regarding situations in this study, intracanal medicaments type and duration of application used in root canals disinfection through RET must be carefully chosen to avoid negative effect on dentin microhardness or DR of MTA jeopardizing the success of the treatment. BAG (S53P4) showed promising results, further studies needed to complete investigations about it as an alternative intracanal medication in RET.

\section{REFERENCES}

1. Silva M., et al. "Revascularization of an Immature Tooth with Apical Periodontitis Using Calcium Hydroxide: A 3-Year Follow- Up". The Open Dent J 2015;9: 482-485.

2. Nicoloso G. "A comparative evaluation of endodontic treatments for immature necrotic permanent teeth based on clinical and radiographic outcomes: a systematic review and meta- analysis". Int J Ped Dent.2017;27: 217-227.
3. Trope M. Treatment of the immature tooth with a nonvital pulp and apical periodontitis. Dent Clin North Am.2010;54:313-324.

4. Andreasen JO, Munksgaard EC, Bakland LK. Comparison of fracture resistance in root canals of immature sheep teeth after filling with calcium hydroxide or MTA. Dent Traumatol 2006;22:154-156.

5. Ostby BN., et al. "The role of blood clot in endodontic therapy". Acta Odonto Scand .1961;19: 323-353.

6. Banchs F and Trope M. "Revascularization of Immature PermanentTeeth with Apical Periodontitis : New Treatment Protocol?”. J Endod 2004;30: 196-200.

7. Lin LM, Ricucci D, Huang GT. Regeneration of the dentine-pulp complex with revitalization/revascularization therapy: challenges and hopes. Int Endod J. 2014;47:71324.

8. Wigler R, Kaufman AY, Lin S, Steinbock N, Hazan-Molina H, Torneck CD. Revascularization: a treatment for permanent teeth with necrotic pulp and incomplete root development. J Endod. 2013;39:319-26.

9. Law AS. Considerations for regeneration procedures. J Endod. 2013;39:S44-56.

10. Rangasamy Vijayaraghavan, Veerabathran Mahesh Mathian, Alagappan Meenakshi Sundaram, Ramachandran Karunakaran, Selvaraj Vinodh: Triple antibiotic paste in root canal therapy. J Pharm \& Bio Sci.2012;4: 230-33.

11. Jong HK, Yuram K, Shei SJ, Jeong WP, Jung IY. Tooth discoloration of immature teeth with a triple antibiotic paste. A case report. J Endod 2010;36:1086-91.

12. Kontakiotis EG, Filippatos CG, Tzanetakis GN, Agraoti A. Regenerative endodontic therapy: a data analysis of clinical protocols. J Endod 2015;41:146-154.

13. Iwaya SI, Ikawa M, Kubota M. Revascularization of an immature permanent tooth with apical periodontitis and sinus tract. Dent Traumatol. 2001;17:185-7.

14. Reynolds K, Johnson JD, Cohenca N. Pulp revascularization of necrotic bilateral bicuspids using a modified novel technique to eliminate potential coronal discoloration: a case report. Int Endod J 2009;42:84-92.

15. Lana PE, Scelza MF, Silva LE, et al. Antimicrobial activity of calcium hydroxide pastes on Enterococcus faecalis cultivated in root canal systems. Braz Dent J 2009;20:32-6.

16. Prabhakar AR, Santhosh Kumar CH. Antibacterial effect of bioactive glass in combination with powdered enamel and dentin. Ind J Dent Res.2010;21:30-4. 
17. Cotti E, Mereu M, Lusso D. Regenerative treatment of an immature, traumatized tooth with apical periodontitis: report of a case. J Endod. 2008;34:611-6.

18. Jung IY, Lee SJ, Hargreaves KM. Biologically based treatment of immature permanent teeth with pulpal necrosis: a case series. J Endod. 2008;34:876-87.

19. Tai B.J., Bian Z., Jiang H., Greenspan D.C., Zhong J., Clark A.E., Du M.Q. Anti-gingivitis effect of a dentifrice containing bioactive glass (NovaMin) particulate. J. Clin. Periodontol. 2006;33:86-91.

20. Jones J.R. Review of bioactive glass: From Hench to hybrids. Acta. Biomater. 2013;9:4457-4486.

21. Du Min Q., Bian Z., Jiang H., Greenspan D.C., Burwell A.K., Zhong J., Tai B.J. Clinical Evaluation of a Dentifrice Containing Calcium Sodium Phosphosilicate (Novamin) for the Treatment of Dentin Hypersensitivity. Am. J. Dent. 2008 21:210-214.

22. Zehnder M., Soderling E., Salonen J., Waltimo T. Preliminary evaluation of bioactive glass S53P4 as an endodontic medication in vitro. J. Endod. 2004;30:220-224

23. Khoroushi M., Mousavinasab S.M., Keshani F., Hashemi $\mathrm{S}$. Effect of resin modified glass ionomer containing bioactive glass on the flexural strength and morphology of demineralized dentin. Oper. Dent. 2013;38:E21-E30

24. Xie D., Zhao J., Weng Y., Park J.G., Jiang H., Platt J.A. Bioactive glass-ionomer cement with potential therapeutic function to dentin capping mineralization. Eur. J. Oral. Sci. 2008;116:479-487.

25. Yang S.Y., Piao Y.Z., Kim S.M., Lee Y.K., Kim K.N., Kim K.M. Acid neutralizing, mechanical and physical properties of pit and fissure sealants containing melt-derived 45S5 bioactive glass. Dent. Mater. 2013;29:1228-1235.

26. Yassen GH, Vail MM, Chu TG, Platt JA. The effect of medicaments used in endodontic regeneration on root fracture and microhardness of radicular dentine. Int Endod J. 2013;46:688-95.

27. Sarkar NK, Caicedo R, Ritwik P, Moiseyeva R, Kawashima I. Physicochemical basis of the biologic properties of mineral trioxide aggregate. J Endod. 2005;31:97-100. Topçuoğlu HS, Arslan H, Akçay M, Saygili G, Cakici F,

28. Guneser MB, Akbulut MB, Eldeniz AU. Effect of various endodontic irrigants on the push-out bond strength of biodentine and conventional root perforation repair materials. J Endod. 2013;39:380-4.

29. Topçuoğlu G. The effect of medicaments used in endodontic regeneration technique on the dislocation resistance of mineral trioxide aggregate to root Canal dentine. Int Endod J. 2014;46:688-95.

30. Garg N, Garg A. Cleaning and shaping of root canal system. In: Textbook of endodontics. 3rd ed. Ch. 18. New Delhi: Jaypee Brothers Medical Publishers (P) Ltd.2014; 246-80.

31. Ting HK, Page SJ, Poologasundarampillai G, Chen S, Yu B, Hanna JV, et al. Phosphate content affects structure and bioactivity of sol-gel silicate bioactive glasses. Int J App Glass Sci. 2017;8(4):372-82.

32. Li R, Clark A, Hench L. An investigation of bioactive glasspowders by sol-gel processing. J App Biomat. 1991;2(4):231-9.

33. Goel A, Sinha bhishek, Khandeparker R S, Mehrotra R, Vashisth P, Garg A.Bioactive Glass S53P4 versus Chlorhexidine Gluconate as Intracanal Medicament in Primary Teeth: An In-vivo Study Using Polymerase Chain Reaction Analysis. J Int Oral Health 2015; 7(8):65-69.

34. Cwikla SJ, Belanger M, Giguere S, Progulske-Fox A, Vertucci FJ. Dentinal tubule disinfection using three calcium hydroxide formulations. J Endod. 2005;31(1):50-52.

35. Nagas E, Cehreli ZC, Uyanik MO, Vallittu PK, Lassila LV. Effect of several intracanal medicaments on the push-out bond strength of ProRoot MTA and Biodentine. Int Endod J 2016;49:184-188.

36. Cruz-Filho AM, Sousa-Neto MD, Savioli RN, Silva RG, Vansan LP, Pécora JD. Effect of chelating solutions on the microhardness of root canal lumen dentin. J Endod. 2011; 37: 358-62.

37. Haapasalo HK, Siren EK, Waltimo TMT, Orstavik D, Haapasalo MPP. Inactivation of local root canal medicaments by dentine: an in vitro study. Int Endod J 2000; 33:126-31.

38. El-Meligy OA, Avery DR. Comparison of apexification with mineral trioxide aggregate and calcium hydroxide. Pediatr Dent 2006;28:248-253.

39. Jeeruphan T, Jantarat J, Yanpiset K, Suwannapan L, Khewsawai P, Hargreaves KM. Mahidol study 1: comparison of radiographic and survival outcomes of immature teeth treated with either regenerative endodontic or apexification methods: a retrospective study. J Endod 2012;38:13301336.

40. Fouad AF, Verma P. Healing after regenerative procedures with and without pulpal infection. J Endod. 2014;40: S58_ S64.

41. AAE: Clinical Considerations for a Regenerative Procedure (2016). 
42. Galler KM, D’Souza RN, Federlin M, Cavender AC, Hartgerink JD, Hecker S, Schmalz G. Dentin conditioning codetermines cell fate in regenerative endodontics. $J$ Endod 2011;37:1536-1541.

43. Lovelace TW, Henry MA, Hargreaves KM, Diogenes A. Evaluation of the delivery of mesenchymal stem cells into the root canal space of necrotic immature teeth after clinical regenerative endodontic procedure. $J$ Endod 2011;37:133-138.

44. Kinney JH, Marshall SJ, Marshall GW. The mechanical properties of human dentin: a critical review and reevaluation of the dental literature. Crit Rev Oral Biol Med 2003;14:13-29.

45. Dogan H, Qalt S. Effects of chelating agents and sodium hypochlorite on mineral content of root dentin. J Endod 2001;27:578-580.

46. Slutzy-Goldberg I, Maree M, Liberman R, Heling I. Effect of sodium hypochlorite on dentin microhardness. J Endod 2004;30:880-882.

47. Oliveira LD, Carvalho CAT, Nunes W, Valera MC, Camargo CHR, Jorge AOC. Effects of chlorhexidine and sodium hypochlorite on the microhardness of root canal dentin. Oral Surg Oral Med Oral Pathol Oral Radiol Endod 2007; 104:125-128.

48. Cruz-Filho AM, Silva RG, Pécora JD. Acción del EDTAC en la microhardness de la dentina radicular en diferentes tiempos de aplicación. Rev Odont Federal Latino Americana (FOLA) 1996;2:82-90.

49. Saoud TM, Zaazou A, Nabil A, et al. Clinical and radiographic outcomes of traumatized immature permanent necrotic teeth after revascularization/revitalization therapy. J Endod. 2014;40:1946_1952.

50. Nikita BR., et al. "Direct effect of intracanal medicaments on survival of stem cells of the apical papilla". J Endod ;2012: 1372-1375.

51. Graham L., et al. "The effect of Calcium hydroxide on solubilisation of bio-active dentine matrix components". J Biomat ;2006: 2865-2873.

52. Kahler B and Rossi-Fedele G. "A review of tooth discoloration after regenerative endodontic therapy". J Endod 2016: 563-569.

53. Chuensombat S., et al. "Cytotoxic Effects and Antibacterial Efficacy of a 3-Antibiotic Combination : An In Vitro Study". J Endod; 2013: 813-819.

54. de Paz S, Perez A, Gomez M, Trampal A, Domínguez Lázaro A. Severe hypersensitivity reaction to minocycline. J Investig Allergol Clin Immunol. 1999;9:403-4.
55. Hench, L.L.;West, J.K. The sol-gel process. Chem. Rev. 1990; 90: 33-72.

56. Massera J., Fagerlund S., Hupa L., Hupa M. Crystallization Mechanism of the Bioactive Glasses, 45S5 and S53P4. J. Am. Ceram. Soc. 2012;95:607-613.

57. Allan I, Newman H, Wilson. Antibacterial activity of particulate bioglass against supraand subgingival bacteria. Biomaterials 2001;22:1683-7.

58. Stoor P, Söderling E, Salonen JI. Antibacterial effects of a bioactive glass plate on oral microorganisms. Acta Odontol Scand 1998,56:161-5.

59. Batur YB, Erdemir U, Sancakli HS. The long-term effect of calcium hydroxide application on dentin fracture strength of endodontically treated teeth. Dent Traumatol. $2013 \mathrm{Ar}$ ticle first published online: Feb 26, 2013.

60. Andreasen JO, Farik B, Munksgaard EC. Long-term calcium hydroxide as a root canal dressing may increase risk of root fracture. Dent Traumatol. 2002;18:134-137.

61. Yassen GH., et al. "Effect of Medicaments Used in Endodontic Regeneration Technique on the Chemical Structure of Human Immature Radicular Dentin : An In Vitro Study”. Journal of Endodontics 39.2 ;2013: 269-273.

62 . Hench LL . The story of Bioglass. J Mater Sci Mater Med. 2006 ; 11:967-78.

63. Hench, L.L. Chronology of bioactive glass development and clinical applications. New J. Glass Ceram. 2013;3: 67-73.

64. Thomas MV, Puleo DA, Al-Sabbagh M. Bioactive glass three decades on. J Long Term Eff Med Implants 2005;15:585-97.

65. Schwendicke F. Incomplete Caries Removal: A Systematic Review and Meta-analysis. J Dent Res 2013; 92: 306-14.

66. Maltz M, Oliveira EF, Fontanella V, Carminatti G. Deep caries Lesions after incomplete dentine caries removal: 40-month follow-up study. Caries Res 2007; 41:493-6.

67. Shibata Y, He LH, Kataoka Y, Miyazaki T, Swain MV. Micromechanical property recovery of human carious dentin achieved with colloidal nano-betatricalcium phosphate. J Dent Res. 2008; 87:233-7

68. Pinheiro HB, Lopes B, Klautau EB, Cardoso J, Silva BR, Cardoso PEC. Influence of bioactive materials used on the dentin surface whitened with carbamide peroxide $16 \%$. Materials Res 2010;13:273-278.

69. Saghiri MA, Shokouhinejad N, Lotfi M, Aminsobhani M, Saghiri AM. Push-out bond strength of mineral trioxide aggregate in the presence of alkaline $\mathrm{pH}$. J Endod. 2010;36:1856-9. 
70. Kawashima N, Wadachi R, Suda H, Yeng T, Parashos P. Root canal medicaments. Int Dent J.2009;59:5-11.

71. Kenee DM, Allemang JD, Johnson JD, Hellstein J, Nichol BK. A quantitative assessment of efficacy of various calcium hydroxide removal techniques. J Endod;2006:32, 563-5.

72. Holland R, Alexandre AC, Murata SS, dos Santos CA, Dezan Junior E. Apical leakage following root canal dressing with calcium hydroxide. Endo \& Dent Trauma;1995:11, 261-3.

73. Chen H, Teixeira FB, Ritter AL, Levin L, Trope M () The effect of intracanal anti-inflammatory medicaments on external root resorption of replanted dog teeth after extended extra-oral dry time. Dent Traumatol.2008;24: 74-8.

74. Huffman BP, Mai S, Pinna L et al. () Dislocation resistance of ProRoot Endo Sealer, a calcium silicate-based root canal sealer, from radicular dentine. Int Endo.2009; 42: 34-46.

75. Panitvisai P, Messer HH. Cuspal deflection in molars in relation to endodontic a restorative procedures. J Endod; 1995:21, 57-61.

76. Da Cunha LF, Furuse AY, Mondelli RF, Mondelli J .Compromised bond strength after root dentin deproteinization reversed with ascorbic acid. J Endod; 2010:36, 130-4.

77. Patil U, Yeli M, Tapashetti S, Naik B, and Tilakchand M. Effect of varying durations of intracanal medicament application used in regenerative endodontic treatment on the push-out bond strength of novel cement: NeoMTA Plus. J Conserv Dent. 2019; 22: 48-53.

78. Kokubo T. Surface chemistry of bioactive glass-ceramics. J Non-Cryst Solids. 1990;120:138-51.

79. Yuan H, Li Y, de Bruijn JD, de Groot K, Zhang X. Tissue responses of calcium phosphate cement: a study in dogs. Biomat. 2000;21:1283-90.

80. Yassen GH, Sabrah AH, Eckert GJ, Platt JA. Effect of different endodontic regeneration protocols on wettability, roughness, and chemical composition of surface dentin. J Endod. 2015;41:956-60.

81. Nerness AZ, Ehrlich Y, Spolnik K, Platt JA, Yassen GH. Effect of triple antibiotic paste with or without ethylenediaminetetraacetic acid on surface loss and surface roughness of radicular dentine.Odontol.2016;104:170-175.
82. Shokouhinejad N, Nekoofar MH, Iravani A, Kharrazifard MJ, Dummer PM. Effect of acidic environment on the push-out bond strength of mineral trioxide aggregate. J Endod. 2010;36:871-4.

83. Yassen GH, Chu TM, Eckert G, Platt JA. Effect of medicaments used in endodontic regeneration technique on the chemical structure of human immature radicular dentin: an in vitro study. J Endod. 2013;39:269-73.

84. Yassen GH, Sabrah AH, Eckert GJ, Platt JA. Effect of different endodonticregeneration protocols on wettability, roughness, and chemical composition of surface dentin. $\mathrm{J}$ Endod. 2015;41:956-60.

85. Felippe WT, Felippe MC, Rocha MJ. The effect of mineral trioxide aggregate on the apexification and periapical healing of teeth with incomplete root formation. Int Endod $\mathrm{J}$; 2006:39, 2-9.

86. Bidar M, Disfani R, Gharagozloo S, Khoynezhad Rouhani A. Medication with calcium hydroxide improved marginal adaptation of mineral trioxide aggregate apical barrier. J Endod;2010:36, 1679-82.

87. Zhang D.,Munukka E., Lepparanta O, Hupa L, Yianen H.O, Salonen J I, Erola E, Viljanen M K, Hupam. Comparison of antibacterial effect of three bioactive glasses. key engineering materials 2006;309:345-348

88. Stanley HR, Clark AE, Pameijer CH, Louw NP. Pulp capping with a modified bioglass formula. Am J Dent. 2001;14:227-32.

89. Yli-Urpo H, Narhi M, Narhi T. Compound changes and tooth mineralization effects of glass ionomer cements containing bioactive glass (S53P4), an in vivo study. Biomater. 2005 ; 26: 5934-41.

90. Crovace MC, Souza MT, Chinaglia CR, Peitl O, Zanotto ED. Biosilicate ${ }^{\circledR}$ - A multipurpose, highly bioactive glass-ceramic. In vitro, in vivo and clinical trials. J NonCryst Solids 2016;432:90-110.

91. Lippert F, Hara AT, Martinez-Mier EA, Zero DT. In vitro caries lesion rehardening and enamel fluoride uptake from fluoride varnishes as a function of application mode. Am J Dent 2013;26:81-85. 